\title{
Neurocognitive changes after awake surgery in glioma patients: a retrospective cohort study
}

\author{
Emma van Kessel ${ }^{1}$ (D) Tom J. Snijders ${ }^{1} \cdot$ Anniek E. Baumfalk ${ }^{1} \cdot$ Carla Ruis $^{1} \cdot$ Kirsten M. van Baarsen $^{1}$. \\ Marike L. Broekman ${ }^{3} \cdot$ Martine J. E. van Zandvoort $^{1,2}$. Pierre A. Robe ${ }^{1}$
}

Received: 10 August 2019 / Accepted: 12 November 2019 / Published online: 4 December 2019

(C) The Author(s) 2019

\begin{abstract}
Purpose Deficits in neurocognitive functioning (NCF) frequently occur in glioma patients. Both treatment and the tumor itself contribute to these deficits. In order to minimize the harmful effects of surgery, an increasing number of patients undergo awake craniotomy. To investigate whether we can indeed preserve cognitive functioning after state-of-the art awake surgery and to identify factors determining postoperative NCF, we performed a retrospective cohort study.

Methods In diffuse glioma (WHO grade 2-4) patients undergoing awake craniotomy, we studied neurocognitive functioning both pre-operatively and 3-6 months postoperatively. Evaluation covered five neurocognitive domains. We performed analysis of data on group and individual level and evaluated the value of patient-, tumor- and treatment-related factors for predicting change in NCF, using linear and logistic regression analysis.

Results We included 168 consecutive patients. Mean NCF-scores of psychomotor speed and visuospatial functioning significantly deteriorated after surgery. The percentage of serious neurocognitive impairments ( -2 standard deviations) increased significantly for psychomotor speed only. Tumor involvement in the left thalamus predicted a postoperative decline in NCF for the domains overall-NCF, executive functioning and psychomotor speed. An IDH-wildtype status predicted decline for overall-NCF and executive functioning.

Conclusions In all cognitive domains, except for psychomotor speed, cognitive functioning can be preserved after awake surgery. The domain of psychomotor speed seems to be most vulnerable to the effects of surgery and early postoperative therapies. Cognitive performance after glioma surgery is associated with a combination of structural and biomolecular effects from the tumor, including IDH-status and left thalamic involvement.
\end{abstract}

Keywords Neurocognitive functioning changes $\cdot$ Glioma $\cdot$ Neuropsychology $\cdot$ Brain tumor $\cdot$ Determinants of neurocognitive functioning

Martine J.E. van Zandvoort and Pierre A. Robe have contributed equally to this paper.

Electronic supplementary material The online version of this article (https://doi.org/10.1007/s11060-019-03341-6) contains supplementary material, which is available to authorized users.

Emma van Kessel

e.vankessel-2@umcutrecht.nl

1 Department of Neurology \& Neurosurgery, University Medical Center Utrecht/UMC Utrecht Brain Center, G03.232, PO Box 85500, 3508 XC Utrecht, The Netherlands

2 Helmhotz Institute, Utrecht University, Room 1715, Heidelberglaan 1, 3584 CS Utrecht, The Netherlands

3 Department of Neurosurgery, Leiden University Medical Center, PO Box 9600, 2300 RC Leiden, The Netherlands

\section{Introduction}

Diffuse gliomas are progressive primary brain tumors that are almost invariably fatal, despite recent advances in treatment. However, since these advances have led to improved life expectancy, researchers and clinicians are simultaneously focusing efforts on maintaining quality of life. One of the major determinants of quality of life in glioma patients is neurocognitive functioning (NCF) [1]. Cognitive deficits occur in a substantial proportion of glioma patients even before any antineoplastic treatment is given, and can occur or worsen as a complication of treatment itself [2].

Awake glioma surgery with intra-operative testing of $\mathrm{NCF}$ aims to reduce the risk of such complications. Since functional brain anatomy and extent of tumor invasion differ 
between individual patients, awake surgery offers the opportunity to maximize tissue resection while sparing cognitive and other neurological functions. In the initial development of awake glioma surgery, the main focus was on language, sensorimotor functions and vision [3, 4]. In recent years, focus is shifting toward other cognitive domains such as executive functioning, psychomotor speed, and memory which are less dependent on one specific location and are more difficult to test intra-operatively [5]. These cognitive domains are found to be frequently impaired in treatmentnaive glioma patients and may also be vulnerable to the effects of surgery and adjuvant treatments $[6,7]$.

Both patient-, treatment-, and tumor-related factors likely play an important role in cognitive changes after surgery. Unraveling the factors that influence cognitive changes after therapy could facilitate the development of new, personalized treatment strategies to maintain cognitive functioning at the best attainable level. It is, however, not yet possible to accurately predict neurocognitive changes after surgery in an individual patient [8-10]. A first step in this path is to quantify neurocognitive changes after therapy across the different cognitive domains, in sufficiently large series of patients. The second step is to correlate preoperative characteristics with these outcomes.

We performed a retrospective study to evaluate NCF in glioma patients before and after surgery and-where applicable-initial adjuvant therapy. The aim of this study is to give an overview of changes in NCF in glioma patients after treatment and to study which factors influence these cognitive changes. We hypothesize that (a) NCF is better preserved in domains that are dependent on specific locations (language, visuospatial functioning) than in domains that are dependent on more widespread cerebral networks (executive functioning, speed and memory), and consequently more difficult to test intraoperatively, and (b) that a combination of patient- and tumor- related factors determine the postoperative neurocognitive outcome $[11,12]$.

\section{Methods}

\section{Design}

We performed a single-center retrospective study, in a consecutive cohort of diffuse glioma patients who underwent neuropsychological testing as part of their routine pre-operative work-up and of the post-operative evaluation for awake brain surgery between 2010 and 2016. Neuropsychological testing took place between 2010 and April 2017.

In the study sample, we studied overall $\mathrm{NCF}$ as well as domain-specific NCF for five neurocognitive domains. Data are reported according to STROBE-criteria (Online Resource 1)). Each neuropsychological test was scored according to standardized scoring criteria. The uncorrected scores were transformed into Z-scores based on the mean and standard deviation of the published norms for normative comparisons. All these neuropsychological data were prospectively collected in a database.

We also collected data about patient-and tumor characteristics (Online Resource Table 1) including data on tumor grade and molecular markers, which were converted into the WHO 2016 classification [13]. More information about the study design can be found in "Online Resource 2".

\section{Analysis}

We performed analyses of neuropsychological functioning data with SPSS (IBM SPSS Statistics, 25.0.0), on two levels of outcome:

1. Group-level: difference of the mean z-value of the study sample as a whole between pre- and post-operative assessment, per domain and for overall neurocognitive functioning. We performed a paired $T$ test to evaluate whether a significant change of mean domain-specific Z-scores occurred. We performed a Wilcoxon relatedsample test instead, if data was not normally distributed.

2. Individual patient-level:

a. by means of percentage of patients with test performance below the threshold of impairment ( -2 standard deviations (SD)) before and after surgery; this was calculated for each domain ("percentage impairment per domain"). To evaluate whether the proportion of patients with impairment differed significantly pre- and postoperatively, we performed a non-parametric McNemar-test that takes into account repeated measures.

b. difference of the NCF scores for each patient between pre and post-operative assessment per domain. We categorized the change in NCF into one of six categories: (1) change of -2 SD or worse; (2) -2 to $-1 \mathrm{SD}$; (3) -1 to $0 \mathrm{SD}$; (4) 0 to $+1 \mathrm{SD}$; (5) +1 to $+2 \mathrm{SD} ;(6)+2 \mathrm{SD}$ or better.

We performed a subgroup analysis for patients who did not receive any treatment after surgery (for both levels of outcome), since changes in NCF scores in this group are not influenced by adjuvant post-operative therapies, and thus form the best representation of the effects of tumor surgery itself on NCF. We further performed subgroup analyses for low-grade glioma (LGG) patients and high-grade glioma (HGG) patients, again for both levels of outcome. 


\section{Determinants of influence on changes in NCF}

To study which determinants were of influence on cognitive changes we also performed analyses of data on two levels of outcome:

1. A delta-Z-score (continuous variable) for overall-NCF, as well as for five domains as described above.

2. The delta-Z-score was dichotomized into cognitive decline (decrease of $\mathrm{Z}$-score of 1 or more) versus no or subtle cognitive decline (decrease of $\mathrm{Z}$-score $<1$, or increase), compared to the preoperative NCF.

We evaluated the predictive value of baseline characteristic (before surgery) on change in NCF, using univariable and multivariable linear and logistic regression analysis.

More details about the analyses are provided in the supplementary methods section (Online Resource 2 ) and in earlier published work (16).

\section{Results}

\section{Clinical characteristics (Online Resource Table 1)}

In total 270 patients underwent awake surgery between 2010 and 2016; 50 patients were excluded based on a diagnosis (non-glioma) or previous anti-tumor treatment; 52 were excluded because of insufficient neuropsychological data. In total 168 patients met our inclusion criteria at baseline and were included.
A total of 34 patients did not undergo post-operative neuropsychological assessment for several reasons (Online Resource Fig. 1), most commonly medical condition or patient refusal.

\section{Neurocognitive data}

The number of patients with severe deterioration or large improvements was low for all different domains, most neurocognitive changes were subtle with a delta-Z-score between -1 SD and +1 SD. Online Resource Fig. 2 depicts the categorized results of the individual-level analyses (regarding changes in percentage of impairment per domain).

Results of NCF analyzed at group level are shown in Fig. 1. Patients' NCF scores slightly, but significantly decreased post-operatively for the domains of visuospatial functioning (mean difference $0.23,95 \%$ confidence interval (CI) -0.39 to -0.08 ) and psychomotor speed (mean difference $0.31(-0.44$ to $-0.1895 \% \mathrm{CI})$ ).

The subgroup analysis for patients $(n=50)$ who did not receive any postoperative treatment showed only significantly decreased mean post-operatively Z-scores for the domain visuospatial functioning [mean difference 0.29 $(-0.53$ to $-0.0695 \% \mathrm{CI})]$.

Subgroup analysis for HGG patients showed significant deterioration for the domain psychomotor speed [mean difference 0.45 ( -0.65 to $-0.2495 \% \mathrm{CI})$ ] and for LGG patients for the domains visuospatial functioning [mean difference 0.33 ( -0.54 to $-0.1195 \% \mathrm{CI})$ ] and psychomotor speed [mean difference $0.15(-0.28$ to $-0.0295 \% \mathrm{CI})$ ].

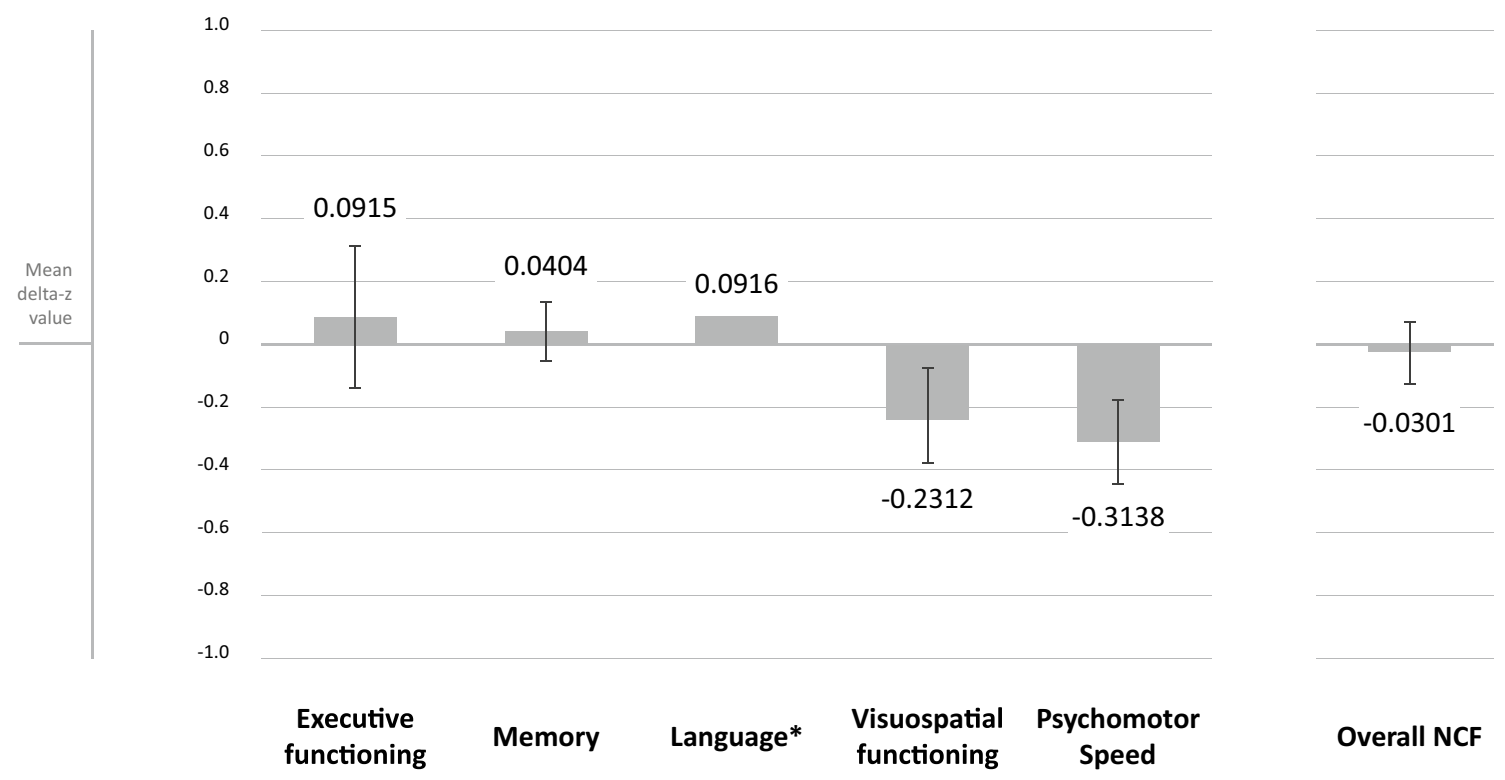

Fig. 1 Group level analyses-post-operative change in mean cognitive scores (Z-scores) per domain. Asterisk: Wilcoxon related sample test performed, because these data was not normally distributed 
Results for subgroup analyses are showed in Online Resource Fig. 3. Group level analyses with pre- and postoperative scores (Z-scores) per domain in boxplots are shown in Online Resource Fig. 4.

The difference between pre- and postoperative proportion of individuals with a serious cognitive impairment (-2SD) is shown in Fig. 2. These differences were only significant for psychomotor speed (preoperatively $22.8 \%$, postoperatively $28.3 \%, \mathrm{p}$ value $=0.008)$.

Subgroup analysis on individual level for patients who did not receive any postoperative treatment (which all were patients with LGG) showed comparable results to those who received post-operative treatment. HGG subgroup analyses did not show any significant postoperative changes. LGG analyses showed a significant increase in patients with an impairment for the domain speed (preoperatively $4.9 \%$, postoperatively $14.8 \%$, p value $=0.031$ ). Results for subgroup analyses on individual level are shown in Online Resource Fig. 5.

\section{Determinants of changes in NCF (Fig. 3)}

The results of the multivariable linear regression analyses are presented in Tables 1, 2, 3, 4, 5, and 6 (for overall-NCF and five cognitive domains). The results of the univariable analyses are shown in Online Resource 3.

We used logistic regression analysis to evaluate baseline characteristics in relation to clinically relevant decline in $\mathrm{NCF}$ as a dichotomous outcome measure (deterioration of $-1 \mathrm{SD}$ or lower versus $>-1 \mathrm{SD}$ ). The results of the univariable analyses are shown in Online Resource 4. Multivariable logistic regression analyses are shown in Tables 7, 8, 9, 10, 11 , and 12.
Figure 3 depicts the significant $(\mathrm{p}<0.05)$ results of both the linear regression analyses for cognitive changes, and the logistic regression analysis for cognitive deterioration.

\section{Discussion}

Through this retrospective study we give an overview of changes in NCF in patients with a diffuse glioma after surgery and initial other anti-tumor treatment and show which factors are of influence on cognitive changes after surgery.

Our results show that the domain psychomotor speed was most vulnerable to the effects of surgery, both on the group level and for the proportion of individual-level deficits. Visuospatial functioning significantly deteriorated after surgery on the group level. In the subgroup of patients who did not receive adjuvant treatment after surgery, results were numerically similar to the whole study sample, underlining that our whole-group results are unlikely to be biased by the effects of radiotherapy or chemotherapy. Surgery (and other therapies) seem to be of greater influence on cognitive functioning in LGG than in HGG patients.

These results support our hypothesis that neurocognitive functioning is mostly maintained after awake surgery across different domains.

This is somewhat in contrast with the findings of Incekara et al., who observed a deterioration in language functions after awake surgery of eloquently located presumed LGGs. Their smaller-scale study was mostly focused at left hemisphere brain regions, whereas our results represent a wider range of glioma patients [14]. Satoer et al., also found postoperative decline in language and executive functions. These differences with our study results can probably be explained by the benefits of awake surgery in our study [7].

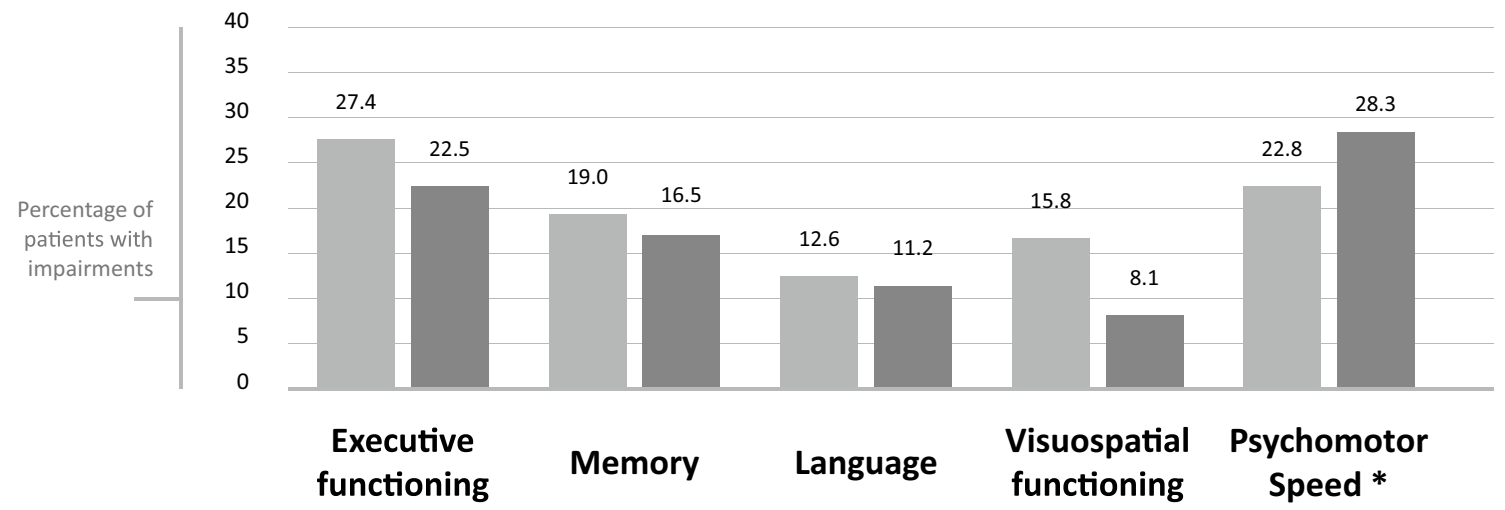

Pre-operative $\quad$ Post-operative

Fig. 2 Individual level analyses-percentage of patients with domain-specific pre- and postoperative impairments 


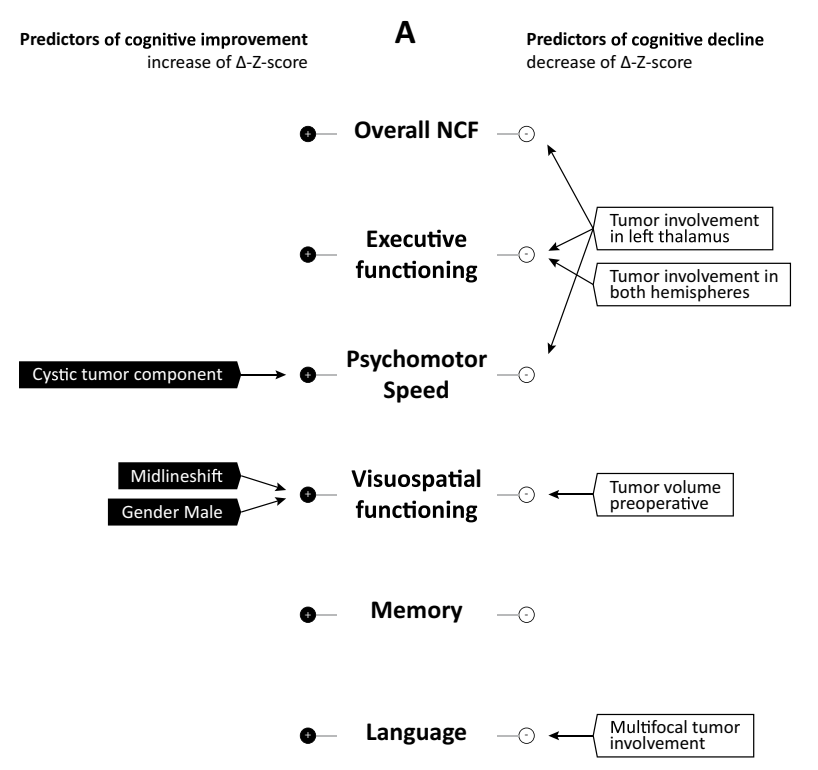

Fig. 3 Summary of results of multivariable linear (a) and logistic (b) regression analyses. a Left side; significant determinants of cognitive improvement (positive mean delta $\mathrm{Z}$-score), right side; determinants

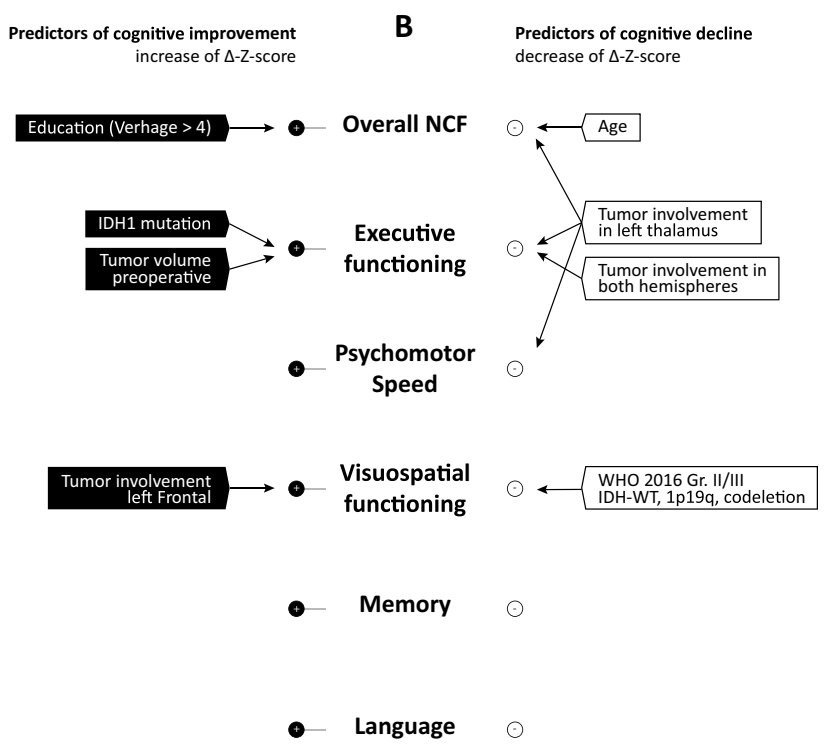

of cognitive decline (negative mean delta Z-score). b Left side; significant determinants of cognitive improvement, right side; significant determinants of cognitive decline (decrease of Z-score of 1 or more)

Table 1 Multivariable linear regression analyses for predicting delta-Z-scores (overall neurocognitive functioning)

\begin{tabular}{|c|c|c|c|c|c|c|}
\hline \multirow[t]{3}{*}{ Baseline variable } & \multirow{2}{*}{\multicolumn{2}{|c|}{ Univariable }} & \multirow{2}{*}{\multicolumn{2}{|c|}{$\frac{\text { Multivariable model } 1}{\mathrm{R}^{2}=0.184 \mathrm{p}=0.006}$}} & \multirow{2}{*}{\multicolumn{2}{|c|}{$\frac{\text { Multivariable model } 2}{\mathrm{R}^{2}=0.426 \mathrm{p}=0.012}$}} \\
\hline & & & & & & \\
\hline & B $(95 \%$ CI $)$ & $\mathrm{p}$ value & B $(95 \% \mathrm{CI})$ & $\mathrm{p}$ value & B $(95 \% \mathrm{CI})$ & $\mathrm{p}$ value \\
\hline Age (at time of surgery) & $-0.009(-0.024$ to 0.006$)$ & 0.249 & $-0.002(-0.021$ to 0.016$)$ & 0.814 & $0.006(-0.014$ to 0.027$)$ & 0.521 \\
\hline Education (4-7 vs. lower) & $1.095(0.175$ to 2.015$)$ & $0.020^{*}$ & $0.823(-0.134$ to 1.781$)$ & 0.091 & $0.703(-0.745$ to 2.152$)$ & 0.331 \\
\hline Tumor volume pre-op & $-0.001(-0.005$ to 0.002$)$ & 0.453 & $0.003(-0.001$ to 0.007$)$ & 0.189 & $0.010(0.003$ to 0.018$)$ & $0.009 *$ \\
\hline IDH1 (mutant vs. WT) & $0.367(-0.083$ to 0.817$)$ & 0.109 & & & $0.909(0.172$ to 1.647$)$ & $0.017 *$ \\
\hline 1p19q deletie (+vs. - ) & $-0.281(-0.685$ to 0.123$)$ & 0.169 & & & $\begin{array}{l}-0.530(-1.006 \text { to } \\
-0.053)\end{array}$ & $0.030 *$ \\
\hline \multicolumn{7}{|l|}{ WHO 2016 (+vs. -) } \\
\hline $\begin{array}{l}\text { Gr. II/III IDH-WT. 1p19q } \\
(-)\end{array}$ & $-0.612(-1.614$ to 0.391$)$ & 0.230 & $-0.871(-1.845$ to 0.103$)$ & 0.079 & & \\
\hline Gr. IV IDH-M & $1.036(-0.134$ to 2.205$)$ & 0.082 & $0.516(-0.766$ to 1.797$)$ & 0.427 & & \\
\hline Gr. IV IDH-WT & $-0.355(-0.855$ to 0.145$)$ & 0.162 & $-0.225(-0.909$ to 0.459$)$ & 0.517 & & \\
\hline \multicolumn{7}{|l|}{ Tumor location (+ vs. -) } \\
\hline Left parietal & $-0.310(-0.810$ to 0.189$)$ & 0.221 & $-0.415(-0.994$ to 0.163$)$ & 0.158 & $0.425(-0.282$ to 1.133$)$ & 0.231 \\
\hline Left thalamus & $\begin{array}{l}-1.336(-2.144 \text { to } \\
-0.528)\end{array}$ & $0.001^{*}$ & $\begin{array}{l}-1.329(-2.294 \text { to } \\
-0.365)\end{array}$ & $0.007 *$ & $-0.087(-1.527$ to 1.354$)$ & 0.904 \\
\hline Right frontal & $-0.314(-0.847$ to 0.220$)$ & 0.247 & $-0.566(-1.162$ to 0.031$)$ & 0.063 & $-0.374(-0.833$ to 0.086$)$ & 0.108 \\
\hline Right temporal & $-0.463(-1.232$ to 0.306$)$ & 0.236 & $-0.403(-1.226$ to 0.419$)$ & 0.334 & $-0.435(-1.031$ to 0.160$)$ & 0.146 \\
\hline
\end{tabular}

$N C F$ neurocognitive functioning, ASA American Society of Anaesthesiologists, $I D H 1$ isocitrate dehydrogenase $1, W T$ wildtype, $M$ mutant, $1 p 19 q 1 \mathrm{p} 19 \mathrm{q}$ deletion, $W H O$ World Health Organization

*Significant $(\mathrm{p}<0.05)$

In more detail, neurocognitive functioning appears harder to preserve in the domain psychomotor speed. This domain is dependent on widespread cerebral networks rather than on specific brain regions [15]. In a previous study we found that "location-independent" domains are affected most in treatment-naive glioma patients [2]. Consistent with this previous 
Table 2 Multivariable linear regression analyses for predicting delta-Z-scores (executive functioning)

\begin{tabular}{|c|c|c|c|c|}
\hline \multirow[t]{3}{*}{ Baseline variable } & \multirow{2}{*}{\multicolumn{2}{|c|}{ Univariable }} & \multicolumn{2}{|l|}{ Multivariable model } \\
\hline & & & \multicolumn{2}{|l|}{$R^{2}=0.150 p=0.009$} \\
\hline & B $(95 \% \mathrm{CI})$ & $\mathrm{p}$ value & B $(95 \%$ CI $)$ & $\mathrm{p}$ value \\
\hline Education (4-7 vs. lower) & $0.454(-0.499$ to 1.407$)$ & 0.248 & $0.159(-0.856$ to 1.175$)$ & 0.757 \\
\hline Tumor volume pre-op & $<0.001(-0.004$ to 0.003$)$ & 0.839 & $0.004(-0.001$ to 0.009$)$ & 0.097 \\
\hline \multicolumn{5}{|l|}{ WHO 2016 (+vs. - ) } \\
\hline Gr. II/III IDH-WT. 1p19q (-) & $-0.966(-1.979$ to 0.047$)$ & 0.061 & $-1.000(-2.031$ to -0.031$)$ & 0.057 \\
\hline \multicolumn{5}{|l|}{ Tumor location (+ vs. - ) } \\
\hline Both hemispheres & $-1.994(-3.486$ to -0.502$)$ & $0.009^{*}$ & $-2.160(-3.673$ to 0.648$)$ & $0.005 *$ \\
\hline Left temporal & $-0.369(-0.833$ to 0.096$)$ & 0.119 & $-0.036(-0.529$ to 0.456$)$ & 0.884 \\
\hline Left thalamus & $-1.011(-1.860$ to -0.162$)$ & $0.020^{*}$ & $-1.319(-2.297$ to -0.342$)$ & $0.009 *$ \\
\hline Brainstem & $-1.321(-3.185$ to 0.543$)$ & 0.163 & $-0.500(-2.439$ to 1.439$)$ & 0.61 \\
\hline \multicolumn{5}{|l|}{ First MRI (+ vs. - ) } \\
\hline Midlineshift & $-0.385(-1.007$ to 0.238$)$ & 0.224 & $-0.384(-1.185$ to 0.417$)$ & 0.345 \\
\hline
\end{tabular}

$N C F$ neurocognitive functioning, ASA American Society of Anaesthesiologists, $I D H I$ isocitrate dehydrogenase 1 , WT wildtype, $M$ mutant, $1 p 19 q 1 \mathrm{p} 19 \mathrm{q}$ deletion, WHO World Health Organization

*Significant $(\mathrm{p}<0.05)$

Table 3 Multivariable linear regression analyses for predicting delta-Z-scores (psychomotor speed)

\begin{tabular}{|c|c|c|c|c|}
\hline \multirow[t]{3}{*}{ Baseline variable } & \multirow{2}{*}{\multicolumn{2}{|c|}{ Univariable }} & \multicolumn{2}{|l|}{ Multivariable model } \\
\hline & & & \multicolumn{2}{|l|}{$R^{2}=0.200 p=0.005$} \\
\hline & $\mathrm{B}(95 \% \mathrm{CI})$ & $\mathrm{p}$ value & B $(95 \%$ CI $)$ & $\mathrm{p}$ value \\
\hline Age (at time of surgery) & $-0.011(-0.020$ to -0.002$)$ & $0.013 *$ & $-0.005(-0.015$ to 0.006$)$ & 0.394 \\
\hline \multicolumn{5}{|l|}{ Education } \\
\hline Verhage 4-7 vs. lower & $0.344(-0.227$ to 0.915$)$ & 0.235 & $0.172(-0.407$ to 0.750$)$ & 0.558 \\
\hline Tumor volume prior to surgery & $0.000(-0.002$ to 0.002$)$ & 0.819 & $0.001(-0.002$ to 0.003$)$ & 0.517 \\
\hline \multicolumn{5}{|l|}{ WHO 2016 (+ vs. -) } \\
\hline Gr. II/III IDH-M. 1p19q (-) & $0.243(-0.080$ to 0.565$)$ & 0.139 & $0.049(-0.292$ to 0.390$)$ & 0.778 \\
\hline Gr. IV IDH-WT & $-0.293(-0.588$ to 0.002$)$ & $0.052 *$ & $-0.023(-0.447$ to 0.401$)$ & 0.914 \\
\hline \multicolumn{5}{|l|}{ Tumor location (+ vs. -) } \\
\hline Left insula & $0.203(-0.060$ to 0.466$)$ & 0.13 & $0.247(-0.030$ to 0.523$)$ & 0.08 \\
\hline Left thalamus & $-0.702(-1.169$ to -0.236$)$ & $0.003^{*}$ & $-0.827(-1.367$ to -0.288$)$ & $0.003^{*}$ \\
\hline \multicolumn{5}{|l|}{ First MRI (+vs. - ) } \\
\hline Cystic & $0.418(0.053$ to 0.782$)$ & $0.025^{*}$ & $0.447(0.058$ to 0.837$)$ & $0.025^{*}$ \\
\hline Enhancement & $-0.294(-0.551$ to -0.037$)$ & $0.025^{*}$ & $-0.161(-0.505$ to 0.183$)$ & 0.356 \\
\hline Necrosis & $-0.290(-0.574$ to -0.006$)$ & $0.045^{*}$ & $0.026(-0.374$ to 0.427$)$ & 0.896 \\
\hline
\end{tabular}

$N C F$ neurocognitive functioning, ASA American Society of Anaesthesiologists, $I D H 1$ isocitrate dehydrogenase 1 , WTwildtype, $M$ mutant, $1 p 19 q 1 \mathrm{p} 19 \mathrm{q}$ deletion, $W H O$ World Health Organization

*Significant $(\mathrm{p}<0.05)$

finding on baseline functioning, we now observe that psychomotor speed also is more vulnerable than other domains to the effects of surgery, other types of therapy (radiotherapy or chemotherapy) and the initial course of the disease.

In subgroup analysis, more LGG patients had cognitive decline after surgery than in HGG patients. Again, this was especially found in the domain psychomotor speed. This finding underscores the vulnerability of LGG patients, who have less cognitive deficits prior to surgery than HGG patients, so probably have more to lose regarding cognition. Another possible explanation for this finding is that HGG patients have more beneficial effect of mass reduction during surgery due to more edema, cystic/necrotic mass lesions and greater overall tumor volume; indeed, pre-operative midline shift, tumor volume and cystic tumor components turned out to predict postoperative cognitive recovery in our analysis. 
Table 4 Multivariable linear regression analyses for predicting delta-Z-scores (visuospatial functioning)

\begin{tabular}{|c|c|c|c|c|}
\hline \multirow[t]{3}{*}{ Baseline variable } & \multirow{2}{*}{\multicolumn{2}{|c|}{ Univariable }} & \multicolumn{2}{|l|}{ Multivariable model } \\
\hline & & & \multicolumn{2}{|l|}{$R^{2}=0.372 p=0.004$} \\
\hline & B $(95 \%$ CI $)$ & $\mathrm{p}$ value & B $(95 \%$ CI $)$ & $\mathrm{p}$ value \\
\hline Male gender (+ vs. - ) & $0.325(0.004$ to 0.646$)$ & $0.048^{*}$ & $0.429(0.066$ to 0.793$)$ & $0.021^{*}$ \\
\hline ASA-score (1 vs. > 1) & $0.342(-0.011$ to 0.696$)$ & 0.058 & $0.304(-0.039$ to 0.647$)$ & 0.082 \\
\hline Tumorvolume prior to surgery & $0.001(-0.001$ to 0.004$)$ & 0.278 & $-0.004(-0.008$ to -0.001$)$ & $0.018^{*}$ \\
\hline \multicolumn{5}{|l|}{ WHO 2016 (+vs. -) } \\
\hline Gr. II/III IDH-M. 1p19q (-) & $-0.220(-0.593$ to 0.153$)$ & 0.246 & $-0.104(-0.565$ to 0.356$)$ & 0.653 \\
\hline Gr. II/III IDH-WT. 1p19q (-) & $-0.594(-1.232$ to 0.045$)$ & 0.068 & $-0.374(-1.028$ to 0.279$)$ & 0.258 \\
\hline Gr. IV IDH-M & $0.511(-0.242$ to 1.265$)$ & 0.182 & $0.230(-0.688$ to 1.148$)$ & 0.619 \\
\hline Gr. IV IDH-WT & $0.388(0.039$ to 0.737$)$ & $0.030^{*}$ & $0.285(-0.296$ to 0.866$)$ & 0.331 \\
\hline \multicolumn{5}{|l|}{ Tumor location (+ vs. - ) } \\
\hline Left hemisphere & $0.433(0.091$ to 0.774$)$ & $0.013^{*}$ & $0.432(-0.086$ to 0.950$)$ & 0.101 \\
\hline Left insula & $0.236(-0.068$ to 0.540$)$ & 0.127 & $-0.140(-0.580$ to 0.300$)$ & 0.527 \\
\hline Left frontal & 0.387 (0.091 to 0.683$)$ & $0.011^{*}$ & $0.200(-0.233$ to 0.633$)$ & 0.36 \\
\hline Left parietal & $0.286(-0.054$ to 0.625$)$ & 0.099 & $-0.109(-0.622$ to 0.404$)$ & 0.673 \\
\hline Cortex involved & $0.859(0.041$ to 1.678$)$ & $0.040^{*}$ & $0.468(-0.476$ to 1.413$)$ & 0.327 \\
\hline Sulcus centralis & 0.203 ( -0.099 to 0.505$)$ & 0.186 & 0.113 ( -0.383 to 1.608$)$ & 0.652 \\
\hline \multicolumn{5}{|l|}{ First MRI (+vs. - ) } \\
\hline Cystic & $0.322(-0.132$ to 0.776$)$ & 0.162 & $0.096(-0.421$ to 0.613$)$ & 0.713 \\
\hline Enhancement & $0.294(-0.008$ to 0.597$)$ & 0.056 & $-0.087(-0.526$ to 0.351$)$ & 0.693 \\
\hline Necrosis & $0.403(0.077$ to 0.728$)$ & $0.016^{*}$ & $-0.048(-0.589$ to 0.494$)$ & 0.862 \\
\hline Midlineshift & $0.769(0.369$ to 1.168$)$ & $<0.001 *$ & $1.254(0.619$ to 1.889$)$ & $<0.001 *$ \\
\hline
\end{tabular}

$N C F$ neurocognitive functioning, ASA American Society of Anaesthesiologists, $I D H 1$ isocitrate dehydrogenase 1 , WT wildtype, $M$ mutant, $1 p 19 q 1 \mathrm{p} 19 \mathrm{q}$ deletion, WHO World Health Organization

*Significant $(\mathrm{p}<0.05)$

Extension of the tumor into the left thalamus was a significant predictor of cognitive decline for overall-NCF, executive functioning and psychomotor speed. About ten percent of the study sample had such thalamic involvement on preoperative T2/FLAIR MRI. Most of these "thalamic lesions" were HGG (11/16). In HGG patients, thalamic involvement most commonly consisted of edema, whereas thalamus involvement in 3 of 5 LGGs was caused by the tumor itself. In none of these patients, the thalamus was resected.

The thalamus, with its cortical, subcortical and cerebellar connections, is known to be a critical node in functional brain networks supporting cognitive functions [16, 17]. Thereby, thalamic lesions can have global and distal effects on cortical network organization [17].

Speculatively, edema and/or infiltrative growth in this region pre-operatively already causes irreversible damage and thereby lessens chance of good cognitive recovery, especially in domains which rely on a widespread network. Another explanation for the negative influence of thalamic involvement on cognitive recovery can be that "thalamic gliomas" form a distinct subgroup of tumors with a specific molecular profile. Such regional variation in glioma biology was illustrated recently by Zhou et al. [18].
Other structural effects we found were a negative influence of larger pre-operative tumor volume and a positive influence of midline-shift on the domain visuospatial functioning. These combined findings suggest that neuropsychological deficits that develop as a result of increased intracranial pressure of the whole brain (represented by midline-shift), are different and more reversible than deficits that arise by direct invasion of the tumor (as represented by preoperative volume). This hypothesis also explains why cystic lesions were associated with postoperative improvement in the domain psychomotor speed: by operating a cystic tumor, intracranial pressure decreases, resulting in a positive effect on this "location-independent" domain.

In the domain executive functioning, larger pre-operative tumor volume was associated with cognitive improvement, which may-again-reflect the positive effect of mass reduction during surgery. In addition to such a structural effect, we found that the classification of the tumor as a grade II/III 1p19q-intact and IDH-wildtype glioma predicted cognitive decline in visuospatial functioning. Also, an IDHmutation predicted favorable recovery in executive functioning. A possible explanation for this finding is that the molecular profile of tumors results in biochemical changes 
Table 5 Multivariable linear regression analyses for predicting delta-Z-scores (memory)

\begin{tabular}{|c|c|c|c|c|}
\hline \multirow[t]{3}{*}{ Baseline variable } & \multirow{2}{*}{\multicolumn{2}{|c|}{ Univariable }} & \multicolumn{2}{|l|}{ Multivariable model } \\
\hline & & & \multicolumn{2}{|l|}{$R^{2}=0.186 p=0.232$} \\
\hline & B $(95 \%$ CI $)$ & $\mathrm{p}$ value & B $(95 \%$ CI $)$ & $\mathrm{p}$ value \\
\hline ASA-score (1 vs. > 1) & $0.185(-0.032$ to 0.403$)$ & 0.093 & $0.152(-0.079$ to 0.383$)$ & 0.194 \\
\hline Tumorvolume prior to surgery & 0.001 (0.000 to 0.003$)$ & 0.053 & $-0.002(-0.004$ to 0.001$)$ & 0.199 \\
\hline \multicolumn{5}{|l|}{ WHO 2016 (+vs. -) } \\
\hline Gr. II/III IDH-M. 1p19q (+) & $-0.184(-0.406$ to 0.039$)$ & 0.105 & $0.034(-0.234$ to 0.303$)$ & 0.799 \\
\hline Gr. IV IDH-M & $0.536(0.051$ to 1.021$)$ & $0.031^{*}$ & $0.089(-0.516$ to 0.695$)$ & 0.770 \\
\hline \multicolumn{5}{|l|}{ Tumor location (+ vs. - $)$} \\
\hline Right hemisphere & $-0.211(-0.437$ to 0.015$)$ & $0.067 *$ & $-0.130(-0.534$ to 0.275$)$ & 0.525 \\
\hline Left frontal & $0.198(0.006$ to 0.391$)$ & $0.044^{*}$ & $0.080(-0.216$ to 0.377$)$ & 0.591 \\
\hline Left parietal & $0.166(-0.053$ to 0.385$)$ & 0.136 & $0.033(-0.317$ to 0.382$)$ & 0.853 \\
\hline Left insula & $0.246(0.052$ to 0.439$)$ & $0.013 *$ & $0.042(-0.279$ to 0.363$)$ & 0.797 \\
\hline Left hippocampus & $0.317(0.063$ to 0.570$)$ & $0.015^{*}$ & $0.136(-0.245$ to 0.517$)$ & 0.480 \\
\hline Multifocal & $-0.764(-1.846$ to 0.317$)$ & 0.164 & $-0.639(-1.749$ to 0.471$)$ & 0.256 \\
\hline Sulcus centralis & $0.139(-0.055$ to 0.333$)$ & 0.159 & $0.168(-0.144$ to 0.480$)$ & 0.286 \\
\hline \multicolumn{5}{|l|}{ First MRI (+ vs. - ) } \\
\hline Cystic & $0.212(-0.068$ to 0.492$)$ & 0.136 & $0.144(-0.191$ to 0.480$)$ & 0.395 \\
\hline Oedema & $0.236(0.039$ to 0.434$)$ & $0.019 *$ & $0.062(-0.256$ to 0.381$)$ & 0.698 \\
\hline Necrosis & $0.201(-0.007$ to 0.408$)$ & 0.058 & $-0.041(-0.358$ to 0.276$)$ & 0.796 \\
\hline Midlineshift & 0.377 (0.122 to 0.633$)$ & $0.004 *$ & $0.415(-0.018$ to 0.848$)$ & 0.060 \\
\hline
\end{tabular}

$N C F$ neurocognitive functioning, ASA American Society of Anaesthesiologists, $I D H I$ isocitrate dehydrogenase 1 , WT wildtype, $M$ mutant, $1 p 19 q 1 \mathrm{p} 19 \mathrm{q}$ deletion, WHO World Health Organization

*Significant $(\mathrm{p}<0.05)$

Table 6 Multivariable linear regression analyses for predicting delta-Z-scores (language)

\begin{tabular}{|c|c|c|c|c|}
\hline \multirow[t]{3}{*}{ Baseline variable } & \multirow{2}{*}{\multicolumn{2}{|c|}{ Univariable }} & \multicolumn{2}{|l|}{ Multivariable model } \\
\hline & & & \multicolumn{2}{|l|}{$R^{2}=0.265 p \leq 0.001$} \\
\hline & B $(95 \%$ CI $)$ & $\mathrm{p}$ value & B $(95 \%$ CI $)$ & $\mathrm{p}$ value \\
\hline Male gender (+vs. - ) & $-0.228(-0.613$ to 0.158$)$ & 0.244 & $-0.300(-0.651$ to 0.051$)$ & 0.094 \\
\hline Tumor volume prior to surgery & $0.003(0.000$ to 0.006$)$ & $0.024 *$ & $0.002(-0.002$ to 0.005$)$ & 0.287 \\
\hline \multicolumn{5}{|l|}{ Tumor location (+ vs. -) } \\
\hline Left temporal & $-0.405(-0.777$ to -0.033$)$ & $0.033^{*}$ & $-0.206(-0.609$ to 0.197$)$ & 0.314 \\
\hline Left thalamus & $-0.444(-1.155$ to 0.267$)$ & 0.219 & $-0.725(-1.441$ to -0.008$)$ & 0.048 \\
\hline Right frontal & $0.350(-0.068$ to 0.769$)$ & 0.1 & $0.150(-0.263$ to 0.564$)$ & 0.473 \\
\hline Multifocal & $-3.528(-5.378$ to -1.678$)$ & $<0.001 *$ & $-3.220(-4.997$ to -1.443$)$ & $<0.001 *$ \\
\hline Cortex involved & $0.887(-0.244$ to 2.017$)$ & 0.123 & $0.737(-0.306$ to 1.779$)$ & 0.164 \\
\hline Sulcus centralis & $0.295(-0.064$ to 0.653$)$ & 0.106 & $0.085(-0.269$ to 0.438$)$ & 0.637 \\
\hline \multicolumn{5}{|l|}{ First MRI (+ vs. - ) } \\
\hline Oedema & $0.518(0.155$ to 0.882$)$ & $0.006^{*}$ & $0.411(-0.024$ to 0.846$)$ & 0.064 \\
\hline
\end{tabular}

$N C F$ neurocognitive functioning, $A S A$ American Society of Anaesthesiologists, $I D H 1$ isocitrate dehydrogenase 1 , $W T$ wildtype, $M$ mutant, $1 p 19 q$ 1p19q deletion, $W H O$ World Health Organization

*Significant $(\mathrm{p}<0.05)$

in the surrounding (and possibly distant) brain parenchyma, with changes in brain functioning, postoperative plasticity and-ultimately-neurocognitive functioning as a consequence. This hypothesis is supported by a recent study by Wefel et al., who found a complex interrelationship between patients' NCF, tumor growth velocity and the presence or absence of an IDH-mutation [19, 20].

Besides the effect of molecular markers on certain genetic pathways, the slower growth of IDH-mutated tumors can be a possible explanation for better cognitive recovery. Further 
Table 7 Multivariable logistic regression analyses (delta-Z-score $=<-1$ SD vs. $>-1$ SD) (overall neurocognitive functioning)

\begin{tabular}{|c|c|c|c|c|}
\hline \multirow[t]{2}{*}{ Baseline variable } & \multicolumn{2}{|l|}{ Univariable } & \multicolumn{2}{|l|}{ Multivariable } \\
\hline & OR $(95 \% \mathrm{CI})$ & $\mathrm{p}$ value & OR $(95 \% \mathrm{CI})$ & $\mathrm{p}$ value \\
\hline Age (at time of surgery) & $1.110(1.050$ to 1.174$)$ & $<0.001 *$ & $1.251(1.035$ to 1.511$)$ & $0.020 *$ \\
\hline Education (Verhage > 4) & $0.192(0.041$ to 0.896$)$ & $0.036^{*}$ & $0.018(0.000$ to 0.819$)$ & $0.039 *$ \\
\hline ASA-score $(>2)$ & 22.444 (1.851 to 272.176$)$ & $0.015^{*}$ & $20.888(0.618$ to 706.271$)$ & 0.091 \\
\hline Histology (glioblastoma) & 8.455 (2.280 to 31.356$)$ & $0.001 *$ & $0.063(0.001$ to 4.172$)$ & 0.197 \\
\hline IDH1 (mutant) & $0.079(0.017$ to 0.372$)$ & $0.001 *$ & $0.037(0.001$ to 1.611$)$ & 0.087 \\
\hline Tumorvolume preoperative T2 & $1.005(0.998$ to 1.012$)$ & 0.180 & $0.982(0.962$ to 1.003$)$ & 0.096 \\
\hline \multicolumn{5}{|l|}{ Tumorlocation } \\
\hline Left thalamus & $17.250(4.167$ to 71.410$)$ & $<0.001 *$ & $83.824(2.509$ to 2800.980$)$ & $0.013 *$ \\
\hline Brainstem & $7.867(0.467$ to 132.427$)$ & 0.152 & $0.318(0.002$ to 61.850$)$ & 0.67 \\
\hline \multicolumn{5}{|l|}{ First MRI } \\
\hline Enhancement & $3.989(1.082$ to 14.713$)$ & $0.038^{*}$ & $0.068(0.002$ to 2.175$)$ & 0.128 \\
\hline Necrosis & $6.673(2.145$ to 20.758$)$ & $0.001 *$ & $3.701(0.221$ to 61.914$)$ & 0.363 \\
\hline
\end{tabular}

$N C F$ neurocognitive functioning, ASA American Society of Anaesthesiologists, $I D H 1$ isocitrate dehydrogenase 1 , WTwildtype, $M$ mutant, $1 p 19 q 1 \mathrm{p} 19 \mathrm{q}$ deletion, WHO World Health Organization

*Significant $(\mathrm{p}<0.05)$

Table 8 Multivariable logistic regression analyses (delta-Z-score $=<-1$ SD vs. $>-1$ SD) (executive functioning)

\begin{tabular}{|c|c|c|c|c|}
\hline \multirow[t]{2}{*}{ Baseline variable } & \multicolumn{2}{|l|}{ Univariable } & \multicolumn{2}{|l|}{ Multivariable } \\
\hline & OR $(95 \% \mathrm{CI})$ & $\mathrm{p}$ value & OR $(95 \% \mathrm{CI})$ & $\mathrm{p}$ value \\
\hline Age (at time of surgery) & $1.042(1.000$ to 1.086$)$ & 0.051 & $0.936(0.836$ to 1.047$)$ & 0.249 \\
\hline Education (Verhage > 4) & $1.001(0.999$ to 1.004$)$ & 0.248 & $0.081(0.001$ to 5.098$)$ & 0.234 \\
\hline ASA-score $(>2)$ & $4.500(0.377$ to 53.734$)$ & 0.235 & $3.312(0.151$ to 72.834$)$ & 0.448 \\
\hline Histology (glioblastoma) & $2.567(0.857$ to 7.684$)$ & 0.092 & $1.557(0.030$ to 80.351$)$ & 0.826 \\
\hline IDH1 (mutant) & $0.151(0.040$ to 0.577$)$ & $0.006^{*}$ & $0.013(0.000$ to 0.339$)$ & $0.009 *$ \\
\hline Tumorvolume preoperative T2 & $1.002(0.994$ to 1.010$)$ & 0.661 & $0.969(0.939$ to 1.000$)$ & $0.048 *$ \\
\hline \multicolumn{5}{|l|}{ Tumor location } \\
\hline Both hemispheres & 18.615 (1.578 to 219.569$)$ & $0.020^{*}$ & 161.265 (1.651 to 15748.513$)$ & $0.030 *$ \\
\hline Left frontal & $6.720(1.454$ to 31.070$)$ & $0.015^{*}$ & $8.351(0.873$ to 79.924$)$ & 0.066 \\
\hline Left thalamus & $4.036(0.921$ to 17.687$)$ & 0.064 & $30.700(1.118$ to 842.879$)$ & $0.043 *$ \\
\hline Brainstem & $8.500(0.503$ to 143.546$)$ & 0.138 & $1.241(0.007$ to 211.880$)$ & 0.934 \\
\hline \multicolumn{5}{|l|}{ First MRI } \\
\hline Enhancement & $2.412(0.728$ to 7.994$)$ & 0.150 & $0.255(0.013$ to 4.978$)$ & 0.368 \\
\hline Necrosis & $3.082(1.036$ to 9.169$)$ & $0.043 *$ & $0.229(0.013$ to 4.103$)$ & 0.316 \\
\hline Midline shift & $2.101(0.603$ to 7.326$)$ & 0.244 & $25.160(0.179$ to 3530.628$)$ & 0.201 \\
\hline
\end{tabular}

$N C F$ neurocognitive functioning, ASA American Society of Anaesthesiologists, IDH1 isocitrate dehydrogenase 1 , WT wildtype, Mmutant, $1 p 19 q 1 \mathrm{p} 19 \mathrm{q}$ deletion, WHO World Health Organization

*Significant $(\mathrm{p}<0.05)$

research into additional associations between tumor biology on the one hand, and neurocognitive functioning and recovery on the other, is needed so anti-tumor treatment can be maximized with minimal adverse effects on NCF.

A limitation of our study is that most $(>70 \%)$ patients received additional therapy after surgery before post-operative neuropsychological assessment was performed. This timing of post-operative neuropsychological assessment was chosen because too early evaluation may be confounded by incomplete postoperative recovery (e.g. edema, supplementary motor area (SMA) syndrome). Since radiotherapy and chemotherapy [21] may influence cognitive functioning, effects of adjuvant therapy cannot be distinguished from the sequelae of surgery. However, our results form a valid representation of the postoperative course of NCF in glioma patients receiving awake brain tumor surgery in or 
Table 9 Multivariable logistic regression analyses (delta-Zscore $=<-1$ SD vs. $>-1 \mathrm{SD})$ (psychomotor speed)
Table 10 Multivariable logistic regression analyses (delta-Zscore $=<-1 \mathrm{SD}$ vs. $>-1 \mathrm{SD})$ (visuospatial functioning)

\begin{tabular}{|c|c|c|c|c|}
\hline \multirow[t]{2}{*}{ Baseline variable } & \multicolumn{2}{|l|}{ Univariable } & \multicolumn{2}{|l|}{ Multivariable } \\
\hline & OR $(95 \% \mathrm{CI})$ & $\mathrm{p}$ value & OR $(95 \% \mathrm{CI})$ & $\mathrm{p}$ value \\
\hline Age (at time of surgery) & 1.047 (1.008 to 1.088$)$ & $0.017 *$ & $0.994(0.932$ to 1.061$)$ & 0.855 \\
\hline Gender (male) & $0.336(0.092$ to 1.226$)$ & 0.098 & $0.214(0.032$ to 1.427$)$ & 0.111 \\
\hline Education (Verhage > 4) & $0.434(0.078$ to 2.419$)$ & 0.341 & $0.391(0.028$ to 5.529$)$ & 0.487 \\
\hline ASA-score $(>1)$ & $2.135(0.638$ to 7.141$)$ & 0.218 & $1.221(0.273$ to 5.458$)$ & 0.794 \\
\hline \multicolumn{5}{|l|}{ WHO2016 } \\
\hline Gr. II/III IDH-M. 1p19q (-) & $0.164(0.021$ to 1.289$)$ & 0.086 & $0.325(0.024$ to 4.385$)$ & 0.397 \\
\hline Gr. IV IDH-WT & $4.511(1.597$ to 12.738$)$ & $0.004^{*}$ & $1.699(0.241$ to 11.987$)$ & 0.595 \\
\hline Tumor volume preoperative $\mathrm{T} 2$ & $1.001(0.994$ to 1.009$)$ & 0.761 & $0.989(0.975$ to 1.003$)$ & 0.116 \\
\hline \multicolumn{5}{|l|}{ Tumor location } \\
\hline Left hemisphere & $2.105(0.572$ to 7.752$)$ & 0.263 & $0.354(0.023$ to 5.428$)$ & 0.456 \\
\hline Left thalamus & 7.143 (1.833 to 27.828$)$ & $0.005^{*}$ & 20.564 (1.625 to 260.212$)$ & $0.020 *$ \\
\hline Right frontal & $0.340(0.074$ to 1.568$)$ & 0.167 & $0.459(0.025$ to 8.291$)$ & 0.598 \\
\hline \multicolumn{5}{|l|}{ First MRI } \\
\hline Enhancement & $5.752(1.582$ to 20.908$)$ & $0.008^{*}$ & $2.189(0.334$ to 14.331$)$ & 0.414 \\
\hline Necrosis & $3.419(1.253$ to 9.325$)$ & $0.016^{*}$ & $0.915(0.157$ to 5.345$)$ & 0.922 \\
\hline
\end{tabular}

NCF neurocognitive functioning, ASA American Society of Anaesthesiologists, IDH1 isocitrate dehydrogenase $1, W T$ wildtype, $M$ mutant, $1 p 19 q 1 \mathrm{p} 19 \mathrm{q}$ deletion, $W H O$ World Health Organization

*Significant $(\mathrm{p}<0.05)$

\begin{tabular}{|c|c|c|c|c|}
\hline \multirow[t]{2}{*}{ Baseline variable } & \multicolumn{2}{|l|}{ Univariable } & \multicolumn{2}{|l|}{ Multivariable } \\
\hline & OR $(95 \% \mathrm{CI})$ & $\mathrm{p}$ value & OR $(95 \% \mathrm{CI})$ & $\mathrm{p}$ value \\
\hline ASA-score $(>1)$ & $0.498(0.173$ to 1.435$)$ & 0.197 & $0.337(0.095$ to 1.190$)$ & 0.091 \\
\hline \multicolumn{5}{|l|}{ WHO2016 } \\
\hline Gr. II/III IDH-WT. 1p19q (-) & 6.741 (1.388 to 32.727$)$ & $0.018^{*}$ & $10.194(1.475$ to 70.474$)$ & $0.019 *$ \\
\hline Tumorvolume preoperative $\mathrm{T} 2$ & 0.997 (0.989 to 1.005$)$ & 0.455 & 1.007 (0.994 to 1.020$)$ & 0.278 \\
\hline \multicolumn{5}{|l|}{ Tumor location } \\
\hline Right hemisphere & $2.286(0.838$ to 6.236$)$ & 0.106 & $0.799(0.118$ to 5.421$)$ & 0.818 \\
\hline Left frontal & $0.266(0.095$ to 0.740$)$ & $0.011^{*}$ & $0.152(0.027$ to 0.844$)$ & $0.031 *$ \\
\hline Left insula & $0.553(0.207$ to 1.482$)$ & 0.239 & $1.605(0.308$ to 8.374$)$ & 0.574 \\
\hline Right parietal & $2.389(0.649$ to 8.795$)$ & 0.19 & $1.576(0.204$ to 12.206$)$ & 0.663 \\
\hline \multicolumn{5}{|l|}{ First MRI } \\
\hline Necrosis & $0.459(0.143$ to 1.471$)$ & 0.19 & $0.357(0.064$ to 1.978$)$ & 0.238 \\
\hline
\end{tabular}

$N C F$ neurocognitive functioning, ASA American Society of Anaesthesiologists, $I D H I$ isocitrate dehydrogenase 1, WT wildtype, $M$ mutant, $1 p 19 q 1 \mathrm{p} 19 \mathrm{q}$ deletion, WHO World Health Organization

*Significant $(\mathrm{p}<0.05)$

Table 11 Multivariable logistic regression analysis; memory

Variables were selected for multivariable logistic regression analysis if a regression equation was found with a $\mathrm{p}$ value of $<0.25$ in univariable analysis. No variables were found with a $\mathrm{p}$ value $<0.25$ in univariable logistic regression analyses

near eloquent brain regions, and standard-of-care adjuvant treatment. Also, subgroup analysis for patients who did not receive any therapy after surgery mostly confirmed the findings from whole-group analyses, suggesting that the influence of chemo- and radiotherapy was limited. In line with this, we also did not correct for extent of resection.
Altogether, we feel that our data reflect the neurocognitive effects of standard-of-care glioma surgery aimed at maximum extent of resection with preservation of brain function.

Secondly, we only included patients in our study sample who underwent awake surgery. Our results are thus primarily generalizable to this specific group of patients, with 
Table 12 Multivariable logistic regression analyses (delta-Zscore $=<-1$ SD vs. $>-1$ SD) (language)

\begin{tabular}{|c|c|c|c|c|}
\hline \multirow[t]{2}{*}{ Baseline variable } & \multicolumn{2}{|l|}{ Univariable } & \multicolumn{2}{|l|}{ Multivariable } \\
\hline & OR $(95 \%$ CI $)$ & $\mathrm{p}$ value & OR $(95 \%$ CI $)$ & $\mathrm{p}$ value \\
\hline Age (at time of surgery) & $1.039(0.990$ to 1.091$)$ & 0.121 & $0.938(0.838$ to 1.050$)$ & 0.268 \\
\hline Education (Verhage > 4) & $0.158(0.025$ to 1.001$)$ & $0.050 *$ & $0.553(0.015$ to 21.024$)$ & 0.749 \\
\hline Histology (glioblastoma) & $7.270(2.107$ to 141.577$)$ & $0.008^{*}$ & $78.084(0.977$ to 6240.664$)$ & 0.051 \\
\hline IDH1 (mutant) & $0.071(0.009$ to 0.594$)$ & $0.015^{*}$ & $0.857(0.010$ to 71.155$)$ & 0.946 \\
\hline Tumorvolume preoperative T2 & $1.004(0.994$ to 1.014$)$ & 0.414 & $0.987(0.962$ to 1.013$)$ & 0.314 \\
\hline \multicolumn{5}{|l|}{ Tumor location } \\
\hline Left temporal & 7.618 (1.503 to 38.612$)$ & $0.014^{*}$ & $8.263(0.581$ to 117.556$)$ & 0.119 \\
\hline Left hippocampus & $3.100(0.699$ to 13.746$)$ & 0.137 & $0.644(0.044$ to 9.480$)$ & 0.749 \\
\hline Left thalamus & $4.857(0.824$ to 28.633$)$ & 0.081 & $5.650(0.249$ to 128.082$)$ & 0.277 \\
\hline Right occipital & $6.625(0.541$ to 81.172$)$ & 0.139 & $20.134(0.273$ to 1485.592$)$ & 0.171 \\
\hline Cortex involved & $0.151(0.012$ to 1.849$)$ & 0.139 & $0.063(0.001$ to 3.397$)$ & 0.174 \\
\hline \multicolumn{5}{|l|}{ First MRI } \\
\hline Necrosis & $6.356(1.540$ to 26.241$)$ & $0.011^{*}$ & $0.218(0.011$ to 4.420$)$ & 0.321 \\
\hline Midline shift & $3.833(0.972$ to 15.116$)$ & 0.055 & $5.878(0.078$ to 443.831$)$ & 0.422 \\
\hline
\end{tabular}

$N C F$ neurocognitive functioning, ASA American Society of Anaesthesiologists, $I D H 1$ isocitrate dehydrogenase 1 , WT wildtype, $M$ mutant, $1 p 19 q 1 \mathrm{p} 19 \mathrm{q}$ deletion, WHO World Health Organization

*Significant $(\mathrm{p}<0.05)$ relatively good clinical performance and a predilection for certain localizations of the tumor [22]. In addition, the percentage of LGG patients is higher in the group of awake surgery patients than in the total glioma population, underscoring that our findings are primarily applicable to in NCF changes after awake surgery.

Selective loss of patients for post-operative assessment $(<20 \%$ of all eligible patients) played a role. Most patients who did not undergo post-operative testing were in clinically bad condition, had already died or refused neuropsychological assessments. Probably these results lead to an underestimation of the real number of patients with postoperative decline in NCF.

Of note, we decided to group tasks on their conceptual background ('domain') in order to enhance power. Such grouping is always complicated since intrinsically more than one concept is tapped in any task. However, neuropsychologists do share common ground in the categorization of tasks across domains [23-25]. We tested for robustness of our test classification by applying an alternative grouping of tests, which only resulted in minimal changes in outcomes.

Analysis of difference scores (before versus after) carries the risk of regression to the mean, especially at the extremes of the spectrum of cognitive scores; we checked for this by repeating group-level analyses for executive functioning and memory, with omission of the most extreme pre-operative Z-values. These sensitivity analyses did not show significant results (mean delta executive functioning 0.0915; independent sample $t$ test $\mathrm{p}=0.225$ and mean delta memory 0.019 ; independent sample $t$ test $\mathrm{p}=0.755$ ).
Strengths of this study include the large sample size and the extensiveness of data on pre- and postoperative NCF. We systematically reported on therapies that could have been of influence on cognitive changes and performed subgroup analysis in a study sample who did not receive any treatment after surgery. Of note, all neuropsychological data were prospectively collected and tested according to a standard clinical procedure leading to a homogeneous set of neuropsychological tasks.

\section{Conclusion}

In patients undergoing awake surgery for a diffuse glioma, cognitive functioning declines after surgery in the domains of visuospatial functioning and psychomotor speed, but not in other domains. It can, therefore, be valuable to pay specific attention to these domains during awake surgery in addition to the more commonly evaluated domains such as language.

Involvement of the thalamus, larger tumor-volume and IDH-mutation were the most important determinants of cognitive outcome after awake surgery. These results underline that a combination of structural and biomolecular effects from the tumor determine postoperative cognitive performance. Deeper knowledge of tumor-genetic markers that predict neurocognitive changes after surgery is necessary and will likely facilitate the development of new strategies for patient counseling as well as treatment and rehabilitation. 
Author contributions All authors participated in conception and/or analysis of this study. All authors contributed to writing of the article and approved the final version. EvK, TJS, MBEvZ and PAR designed the study. EvK and AEB performed data acquisition. EvK, AEB, TJS and MJEvZ performed first analysis. EvK wrote the first draft of the manuscript.

Funding This research was supported by the Ton \& Patricia Bohnenn Fund for Neuro-oncology.

\section{Compliance with ethical standards}

Conflict of interest The authors declare that they have no conflict of interest.

Ethical approval The UMCU institutional ethical review exempted the study from full review; informed consent was not obtained for this observational study on data that were obtained as part of routine clinical care.

Open Access This article is distributed under the terms of the Creative Commons Attribution 4.0 International License (http://creativeco mmons.org/licenses/by/4.0/), which permits unrestricted use, distribution, and reproduction in any medium, provided you give appropriate credit to the original author(s) and the source, provide a link to the Creative Commons license, and indicate if changes were made.

\section{References}

1. Boele FW, Zant M, Heine EC, Aaronson NK, Taphoorn MJ, Reijneveld JC, Postma TJ, Heimans JJ, Klein M (2014) The association between cognitive functioning and health-related quality of life in low-grade glioma patients. Neurooncol Pract 1(2):40-46. https:// doi.org/10.1093/nop/npu007

2. van Kessel E, Baumfalk AE, van Zandvoort MJE, Robe PA, Snijders TJ (2017) Tumor-related neurocognitive dysfunction in patients with diffuse glioma: a systematic review of neurocognitive functioning prior to anti-tumor treatment. J Neurooncol 134(1):9-18. https://doi.org/10.1007/s11060-017-2503-z

3. Ojemann G (2010) Cognitive mapping through electrophysiology. Epilepsia 51(Suppl 1):72-75. https://doi.org/10.111 1/j.1528-1167.2009.02453.x

4. Ruis C (2018) Monitoring cognition during awake brain surgery in adults: a systematic review. J Clin Exp Neuropsychol 40(10):1081-1104. https://doi.org/10.1080/13803395.2018.14696 02

5. Lemee JM, Bernard F, Ter Minassian A, Menei P (2018) Right hemisphere cognitive functions: from clinical and anatomical bases to brain mapping during awake craniotomy. Part II: neuropsychological tasks and brain mapping. World Neurosurg 118:360-367. https://doi.org/10.1016/j.wneu.2018.07.099

6. Satoer D, Visch-Brink E, Smits M, Kloet A, Looman C, Dirven C, Vincent A (2014) Long-term evaluation of cognition after glioma surgery in eloquent areas. J Neurooncol 116(1):153-160. https:// doi.org/10.1007/s11060-013-1275-3

7. Satoer D, Vork J, Visch-Brink E, Smits M, Dirven C, Vincent A (2012) Cognitive functioning early after surgery of gliomas in eloquent areas. J Neurosurg 117(5):831-838. https://doi. org/10.3171/2012.7.JNS12263

8. Wu AS, Witgert ME, Lang FF, Xiao L, Bekele BN, Meyers CA, Ferson D, Wefel JS (2011) Neurocognitive function before and after surgery for insular gliomas. J Neurosurg 115(6):1115-1125. https://doi.org/10.3171/2011.8.JNS11488

9. Talacchi A, Santini B, Savazzi S, Gerosa M (2011) Cognitive effects of tumour and surgical treatment in glioma patients. J Neurooncol 103(3):541-549. https://doi.org/10.1007/s1106 0-010-0417-0

10. Yoshii Y, Tominaga D, Sugimoto K, Tsuchida Y, Hyodo A, Yonaha H, Kushi S (2008) Cognitive function of patients with brain tumor in pre- and postoperative stage. Surg Neurol 69(1):51-61. https://doi.org/10.1016/j.surneu.2007.07.064

11. Corbetta M, Siegel JS, Shulman GL (2018) On the low dimensionality of behavioral deficits and alterations of brain network connectivity after focal injury. Cortex 107:229-237. https://doi. org/10.1016/j.cortex.2017.12.017

12. Hart MG, Ypma RJ, Romero-Garcia R, Price SJ, Suckling J (2016) Graph theory analysis of complex brain networks: new concepts in brain mapping applied to neurosurgery. J Neurosurg 124(6):16651678. https://doi.org/10.3171/2015.4.JNS142683

13. Weller M, Weber RG, Willscher E, Riehmer V, Hentschel B, Kreuz M, Felsberg J, Beyer U, Loffler-Wirth H, Kaulich K, Steinbach JP, Hartmann C, Gramatzki D, Schramm J, Westphal M, Schackert G, Simon M, Martens T, Bostrom J, Hagel C, Sabel M, Krex D, Tonn JC, Wick W, Noell S, Schlegel U, Radlwimmer B, Pietsch T, Loeffler M, von Deimling A, Binder H, Reifenberger G (2015) Molecular classification of diffuse cerebral WHO grade II/III gliomas using genome- and transcriptome-wide profiling improves stratification of prognostically distinct patient groups. Acta Neuropathol 129(5):679-693. https://doi.org/10.1007/s0040 1-015-1409-0

14. Incekara F, Satoer D, Visch-Brink E, Vincent A, Smits M (2018) Changes in language white matter tract microarchitecture associated with cognitive deficits in patients with presumed low-grade glioma. J Neurosurg. https://doi.org/10.3171/2017.12.jns171681

15. Anderson SW, Damasio H, Tranel D (1990) Neuropsychological impairments associated with lesions caused by tumor or stroke. Arch Neurol 47(4):397-405

16. Fama R, Sullivan EV (2015) Thalamic structures and associated cognitive functions: relations with age and aging. Neurosci Biobehav Rev 54:29-37. https://doi.org/10.1016/j.neubi orev.2015.03.008

17. Hwang K, Bertolero MA, Liu WB, D’Esposito M (2017) The human thalamus is an integrative hub for functional brain networks. J Neurosci 37(23):5594-5607. https://doi.org/10.1523/ JNEUROSCI.0067-17.2017

18. Zhou C, Wang Y, Liu X, Liang Y, Fan Z, Jiang T, Wang Y, Wang L (2018) Molecular profiles for insular low-grade gliomas with putamen involvement. J Neurooncol 138(3):659-666. https://doi. org/10.1007/s11060-018-2837-1

19. Wefel JS, Noll KR, Rao G, Cahill DP (2016) Neurocognitive function varies by IDH1 genetic mutation status in patients with malignant glioma prior to surgical resection. Neuro Oncol 18(12):1656-1663. https://doi.org/10.1093/neuonc/now165

20. Wefel JS, Noll KR, Scheurer ME (2016) Neurocognitive functioning and genetic variation in patients with primary brain tumours. Lancet Oncol 17(3):e97-e108. https://doi.org/10.1016/S1470 -2045(15)00380-0

21. Menning S, de Ruiter MB, Veltman DJ, Koppelmans V, Kirschbaum C, Boogerd W, Reneman L, Schagen SB (2015) Multimodal MRI and cognitive function in patients with breast cancer prior to adjuvant treatment - the role of fatigue. Neuroimage Clin 7:547554. https://doi.org/10.1016/j.nicl.2015.02.005

22. Berendsen S, Varkila M, Kroonen J, Seute T, Snijders TJ, Kauw F, Spliet WG, Willems M, Poulet C, Broekman ML, Bours V, Robe PA (2016) Prognostic relevance of epilepsy at presentation in glioblastoma patients. Neuro Oncol 18(5):700-706. https://doi. org/10.1093/neuonc/nov238 
23. Doherty JM, Belletier C, Rhodes S, Jaroslawska A, Barrouillet P, Camos V, Cowan N, Naveh-Benjamin M, Logie RH (2018) Dualtask costs in working memory: an adversarial collaboration. J Exp Psychol Learn Mem Cogn. https://doi.org/10.1037/xlm0000668

24. Biesbroek JM, van Zandvoort MJ, Kappelle LJ, Velthuis BK, Biessels GJ, Postma A (2016) Shared and distinct anatomical correlates of semantic and phonemic fluency revealed by lesion-symptom mapping in patients with ischemic stroke. Brain Struct Funct 221(4):2123-2134. https://doi.org/10.1007/s0042 9-015-1033-8
25. Nys GM, van Zandvoort MJ, de Kort PL, Jansen BP, de Haan EH, Kappelle LJ (2007) Cognitive disorders in acute stroke: prevalence and clinical determinants. Cerebrovasc Dis 23(5-6):408416. https://doi.org/10.1159/000101464

Publisher's Note Springer Nature remains neutral with regard to jurisdictional claims in published maps and institutional affiliations. 